\title{
Sísifo proletario de los dioses: impotencia, repetición y rebeldía
}

\section{Proletarian Sisyphus of the Gods: Impotence, Repetition and Rebellion}

TIPO DE TRABAJO: Comunicación virtual.

PALABRAS CLAVE

Rutina, impotencia, repetición, rebeldía.

KEY WORDS

Routine, impotence, repetition, rebellion.

\section{RESUMEN}

Sísifo proletario de los dioses: impotencia, repetición y rebeldía es una investigación teórica que se basa en mi última investigación práctica titulada Sísifo tres estados. El proyecto Sísifo: tres estados surge a partir del "encuentro fortuito" de un texto de Paul-Henry Chombart de Lauwe por el cual quedé magnetizada. En su libro París y la aglomeración parisina, Chombart estudia durante un año los trayectos realizados por una joven habitante de la capital francesa. Sus recorridos conforman un triángulo de dimensiones reducidas, "sin escapatoria". Los vértices corresponden a su escuela, su domicilio y el de su profesor de piano.

Durante el proyecto Sísifo: tres escenas me apropié del papel del sociólogo francés Chombart de Lauwe para diseccionar la rutina de un habitante de Aladrén, particularmente de Antonio Mateo. Analicé las tres localizaciones que conformaban el engranaje de su rutina, y así, sellé en cada una de ellas su mapa descontextualizado [o paisaje nocturno]. Es una descontextualización, en la cual, despojo todo elemento referencial de dicho mapa. Un mapa que no representa es una distorsión perceptiva. Un elemento cotidiano se torna siniestro cuando lo ampliamos y diseccionamos, al fin y al cabo, es lo que hacemos con nuestra rutina. La repetición visceral del mismo recorrido se torna compleja y desconocida. Creo que la radicalización de la deconstrucción ayuda a convertir el mapa urbano en paisajes nocturnos. Cada nocturno corresponde a una localización concreta del itinerario de Antonio Mateo, el cual transcurre en torno a la naturaleza particular del pueblo. Las fotografías de los mapas están en las fachadas de los lugares establecidos. Como si de una placa honorífica se tratase. El honor de un habitante y de todos a la vez. El acto heroico de levantarse para trabajar, trabajar para vivir, como él, como ella, como yo, como nosotros, como Sísifo.

\section{ABSTRACT}

Proletarian Sisyphus of the Gods: Impotence, Repetition, and Rebellion is a theoretical investigation based on my latest practical research entitled Sisyphus Three States. The project Sisyphus: three states arises from the "fortuitous encounter" of a text by PaulHenry Chombart de Lauwe by which I was magnetized. In his book Paris and the Parisian agglomeration, Chombart studies for a year the journeys made by a young inhabitant of the French capital. Her routes form a triangle of reduced dimensions, "without escape". The apexes correspond to his school, his home and that of his piano teacher.

During the project Sisyphus: three scenes, I appropriated the role of the French sociologist Chombart de Lauwe to dissect the routine of an inhabitant of Aladrén, particularly Antonio Mateo. I analyzed the three locations that made up the gear of his routine, and so I sealed in each of them his decontextualized map [or nocturnal landscape]. It is a decontextualization, in which I strip all referential elements of this map. A map that does not represent is a perceptive distortion. An everyday element becomes sinister when we enlarge and dissect it, after all, it is what we do with our routine. The visceral repetition of the same route becomes complex and unknown. I believe that the radicalization of deconstruction helps to turn the urban map into nocturnal landscapes. Each night corresponds to a specific location of Antonio Mateo's itinerary, which revolves around the particular nature of the village. The 
photographs of the maps are on the facades of the established places. As if it were an honorary plaque. The honour of one inhabitant and of all at the same time. The heroic act of getting up to work, work to live, like him, like her, like me, like us, like Sisyphus.

\section{INTRODUCCIÓN}

Paul-Henry Chombart de Lauwe es un nombre que resuena, como un eco, en mis investigaciones más tempranas.

El azar y la intuición son los engranajes que permanecen activos a lo largo de todos mis procesos de investigación realizados hasta la fecha. El primer atisbo de ello se pudo contemplar en mi exposición individual Vestigio e impotencia en la Sala de la Facultad de Bellas Artes de Málaga en el año 2016.

El planteamiento de Vestigio e impotencia surgió a partir del "encuentro fortuito" de un texto de Paul-Henry Chombart de Lauwe por el cual quedé magnetizada. En su libro París y la aglomeración parisina, Chombart estudia durante un año los trayectos realizados por una joven habitante de la capital francesa. Sus recorridos conforman un triángulo de dimensiones reducidas, "sin escapatoria". Los vértices corresponden a su escuela, su domicilio y el de su profesor de piano. Cuando leí este fragmento sentí una conexión afectiva con la chica de París que me llevó a observar mi propia rutina, desentrañándola de forma obsesiva.

Durante un periodo de ciento cinco días representé mi perímetro personal sobre una plancha de barro negro. Salvando alguna variación, mi día a día conformaba un polígono irregular. Resulta un poco frustrante pensar en la imposibilidad de dejar una huella física de mi transcurrir vital si no es a través del arte. De mi casa al estudio, del estudio a la facultad, de la facultad a la casa.

Por mucho que repitiera el itinerario jamás dejaría vestigio alguno.

\section{METOdOLOGÍA}

Durante el proceso de ejecución de Vestigio e impotencia fuí Chombart de Lauwe y joven parisina de forma simultánea, socióloga y objeto de estudio, adoptando la rutina como un elemento de ensañamiento vital, efectuando un retorcimiento de lo cotidiano donde aflora el sentido freudiano de lo "siniestro" que el propio Freud definiría de la siguiente forma:

"El factor de repetición de lo semejante quizá no sea aceptado por todos como fuente del sentimiento en cuestión. Según mis observaciones, en ciertas condiciones y en combinación con determinadas circunstancias, despierta sin duda la sensación de lo siniestro, que por otra parte nos recuerda la sensación de inanidad de muchos estados oníricos. Cierto día, al recorrer en una cálida tarde de verano las calles desiertas y desconocidas de una pequeña ciudad italiana, vine a dar a un barrio sobre cuyo carácter no pude quedar mucho tiempo en duda, pues asomadas a las ventanas de las pequeñas casas sólo se veían mujeres pintarrajeadas, de modo que me apresuré a abandonar la callejuela tomando por el primer atajo. Pero después de haber errado sin guía durante algún rato, encontréme de pronto en la misma calle, donde ya comenzaba a llamar la atención: mi apresurada retirada sólo tuvo por consecuencia que, después de un nuevo rodeo, vine a dar más allí por tercera vez. Más entonces se apoderó de mi un sentimiento que sólo podría calificar de siniestro." (Freud, 1979, 25).

Vestigio e impotencia consistió en radicalizar lo cotidiano.

La rutina se tornó siniestra cuando tomé la decisión de diseccionarla de forma visceral, justo en un momento, en el cual, me encontraba estudiando el Máster de Producción en la Facultad -donde estaba mi taller-. De mi casa al estudio, del estudio a la facultad, de la facultad a la casa. Al igual que la joven de París, me - nos-encontraba-mos-sin escapatoria.

Cada día-durante ciento cinco días-, al llegar al taller de cerámica, me dedicaba a realizar el plano del itinerario del día anterior, éste quedaba petrificado en una plancha de barro negro-ciento cinco esculturas/itinerarios fueron el resultado-. Un acto de hipostasiar mi espacio y mi tiempo. Como he dicho anteriormente: un ejercicio de radicalizar lo cotidiano y, al mismo tiempo, me imponía un trabajo mecánico y rutinario que generaba una analogía con mi rutina diaria, una metáfora con el transcurrir de mis días. Ser consciente: tirar la piedra para recogerla hasta el fin de mis días. De ahí radica el interés por el absurdo existencialista reflejado en la obra "El mito de Sísifo" de Albert Camus que lo clarifica así:

"El obrero actual trabaja, todos los días de su vida, en las mismas tareas y ese destino no es menos absurdo. Pero solo es trágico en los raros momentos en que se hace consciente. Sísifo, proletario de los dioses, impotente y rebelde, conoce toda la amplitud de su miserable condición: en ella piensa durante el descenso. La clarividencia que debía ser su tormento consuma al mismo tiempo su victoria. No hay destino que no se supere mediante el desprecio". (Camus, 1987, 153). 


\section{DESARROLLO}

Siguiendo la estela de Sísifo y Chombart de Lauwe, afluye la obra Nocturno I-III realizada para la exposición Something must break que tiene lugar en el Convento de Santa Inés en Sevilla-2016-, trabajo que actuará de eje fundamental de Sísifo: tres escenas-2018-, que diseccionaré más adelante.

Nocturno I-III es una serie compuesta por tres fotografías de pequeño formato-15 $\mathrm{x} 20 \mathrm{~cm}$. - en las cuales trabajo con la descontextualización del mapa de mis recorridos. Es una descontextualización, en la cual, despojo todo elemento referencial de dicho mapa. Un mapa que no representa es una distorsión perceptiva. Un elemento cotidiano se torna siniestro cuando lo ampliamos y diseccionamos, al fin y al cabo, es lo que hago con mi rutina. La repetición visceral del mismo recorrido se torna compleja y desconocida.

Creo que la radicalización de la deconstrucción ayuda a convertir el mapa urbano en paisajes nocturnos. Cada nocturno corresponde a una localización concreta de mi itinerario: Nocturno I, es mi hogar; Nocturno II, una parada de autobús; Nocturno III, mi estudio. Tres localizaciones, como los tres vértices del triángulo que conformaban los trayectos de la joven parisina de Paul-Henry Chombart de Lauwe.

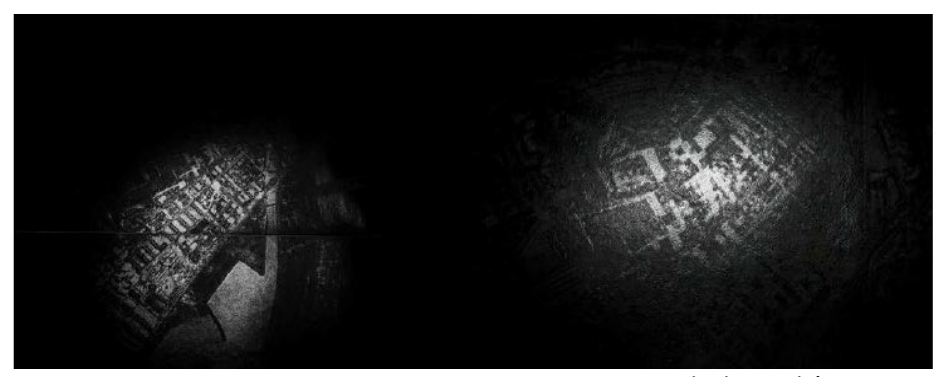

Nocturno I: Hogar.

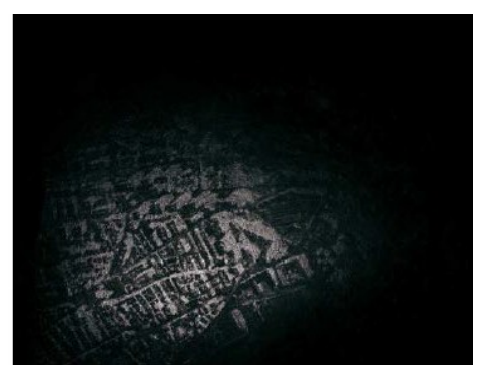

Nocturno III: Estudio.

Llegando al epicentro del congreso, continuaré puntualizando la segunda declinación de la palabra "mapa", que, según la Real Academia Española, atiende a una representación geográfica de la superficie terrestre, en la que se da información relativa a la ciencia determinada. A lo que Carmen Osuna podría contestar:

“¿Realmente existe eso que llamamos mapas? Dibujar un mapa es en definitiva analizar para abstraer, congelar el espacio en el tiempo, perder lo empírico...la vida en sí." (Osuna, 2016,10).

Parto del mapa para desposeerlo del sistema de códigos que lo define como tal, erradico la referencialidad para transformarlo en imagen contemplativa, por lo tanto, atiendo a un leguaje meramente pictórico. Sabemos que cada Nocturno pertenece a un lugar porque lo especifico en el título de la obra, no por la imagen en sí, lo que me lleva directamente a la obra de "El ferrocarril” (1874) de Èduard Manet y la lectura que hace el historiador Victor I. Stoichita en su libro "Ver y no ver" sobre la pintura Impresionista:

"Lo que el título del cuadro anuncia no se muestra. No es que el ferrocarril no esté allí, sino que su imagen queda velada, escondida, inaccesible. La tensión entre lo que el título promete y lo que se ve en el cuadro impulsa al espectador a buscar una explicación". (Stoichita, 2005, 15).

Esa "tensión" título-cuadro/ventana, se repite en los Nocturnos, sin embargo, creo que-en este caso particular- a ojos del espectador el título (localizador) actúa como un paradigma referencial, es decir: Nocturno I: Hogar, es mi hogar porque lo estoy especificando y, a su vez, genero un vínculo empático con el espectador:

Mi hogar es su hogar y puede ser cualquier lugar cuando lo despojamos de cualquier código del lenguaje "mapa".

\section{Sísifo: tres escenas}

Tanto Vestigio e impotencia como la serie de Nocturnos son investigaciones autorreferenciales en los que-como he mencionado con anterioridad-me apropio del fragmento del libro de París y la aglomeración parisina para hablar de mi propia rutina adoptando tanto el papel del sociólogo Chombart de Lauwe como el de la joven habitante de París. Sin embargo, en el proyecto Sísifo tres estados me convierto directamente en socióloga para diseccionar la rutina de un habitante del pueblo de Aladren (Aragón), gracias a la beca internacional de residencia ABABOL Festival. 
El festival $A B A B O L$ se centra en el arte público, la memoria y despoblación. El último de los factores es el que más afecta al pueblo aragonés de Aladrén-situado en el campo de Cariñena- que cuenta con cincuenta y dos habitantes. Durante la semana de duración del festival- del 17 al 23 de septiembre-desarrollé el proyecto Sísifo: tres escenas, en el cual, me apropié del papel del sociólogo francés Chombart de Lauwe para diseccionar la rutina de un habitante de Aladrén, particularmente de Antonio Mateo, y así, analicé las tres localizaciones que conformaban el engranaje de su rutina, al igual que en la obra Nocturnos I-III -explicada con anterioridad-.

Antonio Mateo tiene 85 años. Mateo-como se le conoce en el pueblo-y su mujer, Pilar, regresaron a Aladrén tras vivir cerca de cincuenta años en Francia y, como el mismo dice, "le devolvió la vida".

La rutina de Mateo gira en torno a la naturaleza. Después de desayunar con Pilar, se va con su perro a la Ermita de San Clementeen plena montaña-. Cuando regresa le dedica unas horas a su huerto para después irse al pantano a pescar. Otros días se va a la Fuente Macario- construida por él- para después seguir subiendo por la montaña a dar sal a las cabras montesas.

Por lo tanto, los tres engranajes fundamentales de su rutina son:

Sísifo 1o escena: Hogar de Mateo.

Sísifo 2o escena: Ermita de San Clemente.

Sísifo 3o escena: Fuente Macario.

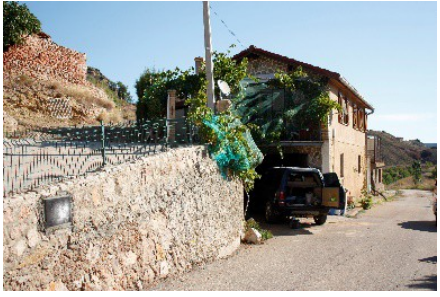

Sísifo 1o escena: Hogar de Mateo.

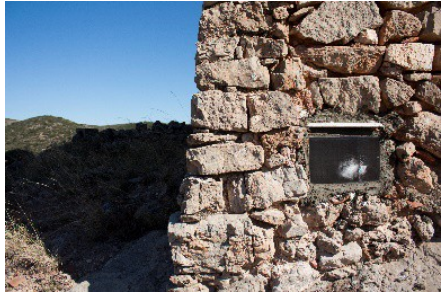

Sísifo 2o escena: Ermita de San Clemente. Sísifo 3 escena: Fuente Macario.

Llegados a este punto he de puntualizar que, mientras que la obra Nocturnos era una serie fotográfica pensada para un lugar expositivo-Sala Santa Inés, Sevilla-, la obra Sísifo: tres estados es una obra de arte público donde cada una de las imágenes-realizadas en losa cerámica- se encuentran fijadas en el lugar específico de cada una de las paradas rutinarias de Mateo. Las cerámicas de los mapas descontextualizado que actúan como paisaje nocturno están en las fachadas de los lugares establecidos. Como si de una placa honorífica se tratase. El honor de un habitante y de todos a la vez.

El acto heroico de levantarse para trabajar, trabajar para vivir, como él, como ella, como yo, como nosotros, como Sísifo. Al hacer el recorrido para ver las placas, estás formando parte de la rutina de Mateo, estás siendo parte de Aladrén.

\section{CONCLUSIONES}

La definición de paisaje nocturno para hablar de la descontextualización del mapa que torna a imagen contemplativa, deviene del movimiento del Romanticismo, tanto pictórico como literario, que, definiría Esperanza Guillén en su libro "Naufragios"-editorial Siruela- como:

\footnotetext{
"El poder de la naturaleza enfrenta al sujeto con el delirio, con su propia incertidumbre ante situaciones que no puede dominar; lo enfrenta al ámbito de lo incognoscible y otro orden de percepción de lo real que se transfigura en vértigo ante lo que le sobrecoge y al mismo tiempo lo atrae". (Guillén, 2004, 9).
}

Y la cita que puede sintetizar más la metáfora entre paisaje y mapa descontextualizado-realidad velada-sería la siguiente, perteneciente al mismo libro y misma autora:

"La impotencia del sujeto ante la realidad hostil, transformada en violencia inmóvil”. (Guillén, 2004,10).

La realidad hostil a la que se refiere Guillén, la entiendo como alegoría de la rutina, y, el sentimiento romántico del sobrecogimiento ante la naturaleza es para mí, en la contemporaneidad, como un sobrecogimiento hacia la impotencia del transcurrir de los días. Una 
imagen que se reitera hasta la saciedad se tornará siniestra, obstaculizando nuestras miradas, surgiendo así, el retorcimiento perceptivo de lo real.

Vuelvo a Albert Camus para finalizar con otro fragmento de su obra "El mito de Sísifo", que - como se ha podido apreciar a lo largo del escrito-, el absurdo existencialista adopta un papel crucial, del cual, ha ido girando el desarrollo de la presente investigación, resucitando la siguiente cita esclarecedora:

"Cada uno de los granos de esa piedra, cada fragmento mineral de esa montaña llena de noche, forma por sí solo un mundo. La lucha por llegar a las cumbres basta para llenar un corazón de hombre". (Camus, 1987, 156).

\section{FUENTES REFERENCIALES}

Camus, A. (1987). El mito de Sísifo. Madrid: Alianza.

Freud, S. (1979). Lo siniestro. Barcelona: CALAMVS SCRIPTORIVS.

Guillén, E. (2004). Naufragios. Madrid: Siruela.

Stoichita, V. I. (2005). Ver y no ver. Madrid: Siruela.

Maldonado, V., Osuna Luque, C. y Zurita, J. (2016). Vestigio e impotencia. Málaga: Maringa S.L. 